\title{
An den christlichen Adel deutscher Nation von des christlichen Standes Besserung
}

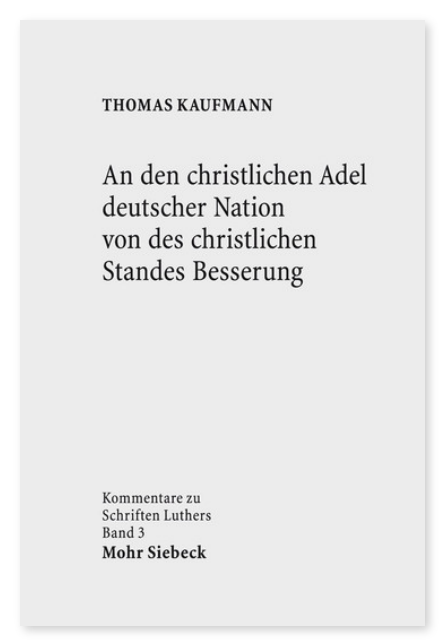

2014; unveränderte Studienausgabe; 2016. XV, 559 Seiten. KSLuth 3

ISBN 978-3-16-154576-4

DOI 10.1628/978-3-16-154576-4

eBook PDF 69,00€

ISBN 978-3-16-154324-1

Broschur 69,00€
Die Adelsschrift ist ein Schlüsseldokument der frühen Reformation; in ihr zeigt sich Luther erstmals als jener Reformator, der das lateineuropäische Kirchenwesen in seiner bestehenden Form radikal in Frage stellte. Im Spiegel der hier erstmals vollständig kommentierten Adelsschrift stellt sich die Reformation als radikaler Traditionsbruch dar. Thomas Kaufmann erläutert sie deshalb sprachlich, historisch-sachlich und theologiegeschichtlich und interpretiert sie in ihrem historischen Kontext.

"[Kaufmanns] Kommentar zur Adelsschrift wird sich seinen Platz unter den Hilfsmitteln zum Lutherstudium bei Fachkollegen zweifellos erobern.«

Armin Kohnle in Luther, 86. Jahrgang 2015, H.1, S. 49/50

»Zweifelsohne ist Kaufmann ein Standardwerk zu einem sehr speziellen Thema gelungen, das seine reichen Inhalte durch interessierte Lektüre entfalten wird.«

Stefan Michel auf www.sehepunkte.de/2014/09/24474.htm/

»[Kaufmann] schöpft aus dem Vollen seiner nunmehr über 25-jährigen Beschäftigung mit Luther und der frühen Reformationszeit in Wittenberg und akzentuiert seine Deutungen im Kontext der in Göttingen seit langem verfolgten Reformationsdeutung unter besonderer Berücksichtigung ihres literarischen Schaffens und der publizistischen Breitenwirkung."

Markus Wriedt in Archiv für Reformationsgeschichte 43 (2014), S.18/19

»Dass dieser Kommentar eine exzeptionelle wissenschaftliche Leistung darstellt, steht außer Frage. Zugleich mag er freilich auch als ein impliziter Mahnruf im Vorfeld des 2017 zu begehenden Reformationsgedenkens verstanden sein."

Albrecht Beutel auf www.th/z.de/buch_des_monats.php

Thomas Kaufmann Geboren 1962; Studium der Theologie in Münster, Göttingen, Tübingen; 1990 Promotion; 1994 Habilitation; 1996-2000 Lehrstuhl für Kirchengeschichte an der LMU München; seit 2000 Lehrstuhl für Kirchengeschichte in Göttingen; 2020 Leibnizpreis.

https://orcid.org/0000-0002-5003-8731

Jetzt bestellen:

https://mohrsiebeck.com/buch/an-den-christlichen-adel-deutscher-nation-von-des-christlichen-standes-besserung9783161545764?no_cache $=1$

order@mohrsiebeck.com

Telefon: $+49(0) 7071-923-17$

Telefax: $+49(0) 7071-51104$ 